\title{
Rainfall and Soils, Not Grazing Intensity, Determine the Composition and Productivity of Annual Plants in a Biodiverse Arid Winter Rainfall Region
}

\author{
Martha M. Konje $^{1} \quad$ Paul K. Muoria ${ }^{1} \quad$ Emily Wabuyele $^{1} \quad$ Neil Griffin $^{2} \quad$ Susanne Vetter $^{3}$ \\ 1.Kenyatta University, Department of Plant Sciences, P.O. Box 43844 - 00100, Nairobi, Kenya \\ 2.Institute for Water Research, Rhodes University, P.O. Box 94, Grahamstown, South Africa \\ 3.Department of Botany, Rhodes University, P.O. Box 94, Grahamstown, 6140, South Africa
}

The research work was financially supported by the South Africa National Research Foundation, through Rhodes University, South Africa.

\section{Abstract}

Concentration of grazer activity around watering points and stock posts has led to well-documented vegetation impacts in arid and semi-arid rangelands. Effect of grazing and abiotic factors on perennial plant diversity have been reported in the bio-diverse winter rainfall vegetation of the Succulent Karoo in South Africa, but the impact on annuals had not been investigated. The aim of this study was to assess the effect of rainfall, soil nutrients, land forms and grazing on forage depletion, soil chemistry and the composition, diversity, richness and biomass production of annual plants in the Richtersveld National park, which is a contractual national park used by seminomadic pastoralists to herd goats and sheep. A grazing gradient away from stock posts at $100 \mathrm{~m}, 500 \mathrm{~m}$ and $1000 \mathrm{~m}$ on sandy plains and rocky foothills at five study sites with different mean annual rainfall and vegetation types were used. Distance from stock posts corresponded to a gradient of forage depletion and resulted in changes in soil chemistry with distance. Biomass production, richness and diversity of annuals were correlated with rainfall but not significantly affected by landform or distance from stock posts. Rainfall and soil variables had a greater influence on species composition than grazing in this arid ecosystem. The decrease in perennial cover and richness near the stock posts was not accompanied by increase in biomass production or richness of annuals, which is expected to have adverse effects on overall plant diversity and forage availability.

Keywords: Piosphere, Pastoralists, Rangeland, Succulent Karoo

DOI: $10.7176 / \mathrm{JNSR} / 12-10-04$

Publication date:May $31^{\text {st }} 2021$

\section{Introduction}

Drylands support the livelihoods of millions of pastoralists. Pastoralist systems are adapted to tracking high degrees of spatial and temporal climatic variability, with livestock grazing being spatially and seasonally constrained by the availability of water. While traditional nomadic pastoralists had very limited year-round impact in most arid regions due to the absence of perennial water; their population growth and sedentarization around settlement and permanent watering points have resulted in unprecedented livestock densities that are able to access an increasing proportion of the world's arid vegetation. This has resulted in rangeland degradation, loss of biodiversity and conflict with conservation in many areas.

The establishment of watering points and stock posts in arid and semi-arid rangelands has had significant impacts on dryland biodiversity, as they result in herbivores to be concentrated year-round in areas where the vegetation evolved with low and transient herbivore densities (Jawuoro et al., 2017). In the vicinity of stock posts and watering points, grazers generate areas of altered soils and vegetation known as piospheres, where grazing, trampling and animal waste are highly concentrated (Nsinamwa et al., 2005, Brooks et al., 2006). Daily grazing movements around stock posts and watering points causes grazing-induced gradients in soil nutrient availability due to increased deposition of dung and urine around the stock posts.

The Succulent Karoo in South Africa is a biodiversity hotspot and has the highest plant biodiversity of the world's arid regions (Mucina \& Rutherfold, 2006). The Namaqualand region of the Succulent Karoo is renowned for its spectacular displays of winter and spring annuals, but interest in the region's plant diversity has focused on the perennial plants with their high levels of endemism and recent evolutionary radiation in the Aizoaceae (Gilson \& Hoffman, 2007). Negative effects of grazing on perennial shrub cover, diversity and richness have been widely reported in several studies in Namaqualand (Hendricks et al., 2005b; Anderson et al., 2010). One of the major impacts of heavy grazing has been a replacement of palatable perennial shrub species with unpalatable ones and a shift in dominance from perennial shrubs to annuals (Tarhouni et al., 2010). Grazing impacts are particularly pronounced in the more densely settled communal rangelands, where semi-nomadic pastoralists keep their goats and sheep at stock posts overnight, which concentrates grazing, trampling and the deposition of dung and urine.

Heavy grazing in the Succulent Karoo is generally associated with changes in plant composition resulting in 
an increase in annual and unpalatable perennial species and a decrease in palatable perennial species, (Todd \& Hoffman, 2009; Rutherford \& Powrie, 2010), and reduction in grazing pressure has been observed to lead to a reverse trend (van Rooyen et al. 2015). The effect of grazing pressure and resultant compositional changes on species richness and diversity in the Succulent Karoo has been less clear-cut. Some authors found no significant difference in species richness and/or diversity with increased grazing pressure (Todd \& Hoffman, 2009; Anderson \& Hoffman, 2007), while Hendricks et al., (2005b) reported a decline in species richness along a grazing intensity gradient and reported an increase in species richness at higher grazing pressure (Rutherford \& Powrie, 2010)

Arid and semi-arid areas which are characterized by short growing seasons, high frequencies of drought and great intra- and inter-annual rainfall variability, which results in fluctuations of primary production from year to year ( Jeddi and Chaieb, 2010). This is particularly true for annual-dominated vegetation because the biomass of annuals is especially strongly rainfall-driven (Gilson and Hoffman, 2007, van Rooyen et al., 2010). Annuals have disturbance-adapted life histories. They are good colonizers but poor competitors and able to occupy gaps created by cover loss of perennials as a result of continuous grazing. Annuals also have been found to be favored by nutrient concentration by grazers around the piosphere points (Shahriary et al., 2012). On the other hand, annuals are not reliable source of forage especially during the dry seasons because they are short-lived, rainfall dependent and suffer loss of seed set (van Royeen et al., 2010). According to Sassi et al., (2009), when annuals are subjected to water stress they usually have a short life span, with relatively fewer inflorescence and shorter flowering period which eventually affect the seed sets and biomass production. Annual plants are an important, though variable source of food in the Succulent Karoo (Hendricks et al., 2005b). Annuals are very productive during high rainfall years and provide high quality forage (van Rooyen et al., 2010), which can compensate for the loss in perennial productivity and allow degraded rangelands to retain levels of secondary production in years of average to high rainfall (Fynn and O'Connor, 2000). During drought periods, however, germination and establishment of annuals are much reduced, making them an unreliable source of forage and exacerbating rather than buffering the effects of climate variability on herbivore populations (Tefera, 2013).

The Succulent Karoo in South Africa is a biodiversity hotspot that has been used for grazing for the last 2000 years, but since colonial period fences and windmills have allowed continuous utilization by livestock and this has had major impacts on plant diversity (Mucina et al., 2006). It is a winter rainfall desert with extraordinarily high plant diversity and endemism, including the world's richest succulent flora (Baker \& Hoffman, 2006). Outside formal reserves, land use is primarily focused on agriculture, with livestock grazing as a dominant land use in $90 \%$ of the region (Petersen et al., 2004). Although grazing is a form of land use that is theoretically compatible with biodiversity conservation, overgrazing has had a negative effect on both annual and perennial plants (Anderson \& Hoffman, 2007). In addition, human population pressure and climate change present huge challenges in conservation of this biodiversity rich ecosystem (Mucina \& Rutherfold, 2006). The unique botanical diversity of Succulent Karoo has provided justification for conservation planning based on plant diversity (Mucina et al., 2006). Despite their importance as forage for livestock, and their abundance in the winter-spring rainfall season when they produce charismatic mass-flowering displays, there is relatively little information available on the diversity and productivity of annual plants in the Succulent Karoo and how it is affected by grazing, rainfall variability and soil nutrients. In the context of the pastoral system, it is of interest whether there is an increased productivity of annuals in heavily grazed areas near stock posts, and whether this could to some degree compensate for the loss in perennial cover and hence productivity.

Many studies done in the South African Succulent Karoo have demonstrated the effect of rainfall variability on plant communities as well as on properties of soils (Petersen et al., 2004). By comparison, there is little information available on the effect of grazing and abiotic factors on the composition, diversity and primary productivity of annual plants in the Succulent Karoo as well as in other arid rangelands worldwide (Anderson \& Hoffman, 2007). Of particular interest in the context of the pastoral system in the RNP is whether there is increased productivity of annuals near stock posts, and whether annual plants could to some degree compensate for the loss of shrub cover in rangelands (Hendricks et al., 2005a).

The Richtersveld National Park (RNP) is an arid ecosystem that has been under the same land use practices for decades with pastoralists using the conventional stock posts distributed in the five study sites that fall within 5 vegetation types and 2 biomes. The park faces the challenge of grazing management in terms of controlling herd numbers and movement as well as the ability to monitor impacts of land use practices on biodiversity because there is no approved management plan for the park (Hendricks et al., 2005a). Pastoralists herd their animals whenever and wherever they want and with as many herbivores as they want. Continuous grazing, erratic winter rainfall and climate change scenarios in this arid ecosystem pose high risks to the landscapes with rare, threatened or endemic species that require special conservation interest (Hendricks et al., 2005b). Hendricks et al. (2005a) found that species richness, diversity and cover of perennial shrubs increased with distance away from the stock posts in Richtersveld National Park

The aim of this study was to assess the effect of rainfall, soil nutrients, land forms and grazing on 
composition, richness and biomass production of annual plants in the RNP, and to determine whether the decline in perennial cover was accompanied by an increased abundance of annual plants close to stock posts. We expected that forage depletion would decrease with distance away from stock posts and would be lower in foothills than flat plains. Our assumption was that soil variables would vary with distance from stock posts and between plains and foothills in line with grazing intensity closer to stock posts and on plains. It was expected that biomass, richness, diversity of annuals to increase with rainfall, while the effect of grazing could be negative or positive, depending on the net effect of direct and indirect grazing. It was expected that the composition of annuals to differ between the two biomes and the five vegetation types and to be influenced by rainfall, soil variables and grazing intensity (landform and distance from stock posts

\section{Materials and Methods \\ 2.1 Study area}

The study was done in the Richtersveld National Park (RNP) which is located in the semi-arid region of the Namaqualand magisterial district $\left(28^{0} 15^{\prime} \mathrm{S}, 17^{0} 10^{\prime} \mathrm{E}\right)$ in the north-western part of South Africa (Figure 1). The park is located immediately south of the Orange River which marks the international border with Namibia. It covers a total area of 162,445 ha and forms part of the larger Richterveld communal rangeland that is 513,919 ha (Mucina et al., 2006). The RNP is a winter rainfall area, with high inter-annual rainfall variability. The area has a mean annual rainfall of $72 \mathrm{~mm}$ (Mucina \& Rutherfold, 2006). The park is located where two major climate systems meet, that is the warm temperate winter rainfall experienced from the mountain range on the west and subtropical summer rainfall found to the east (Young et al., 2016).

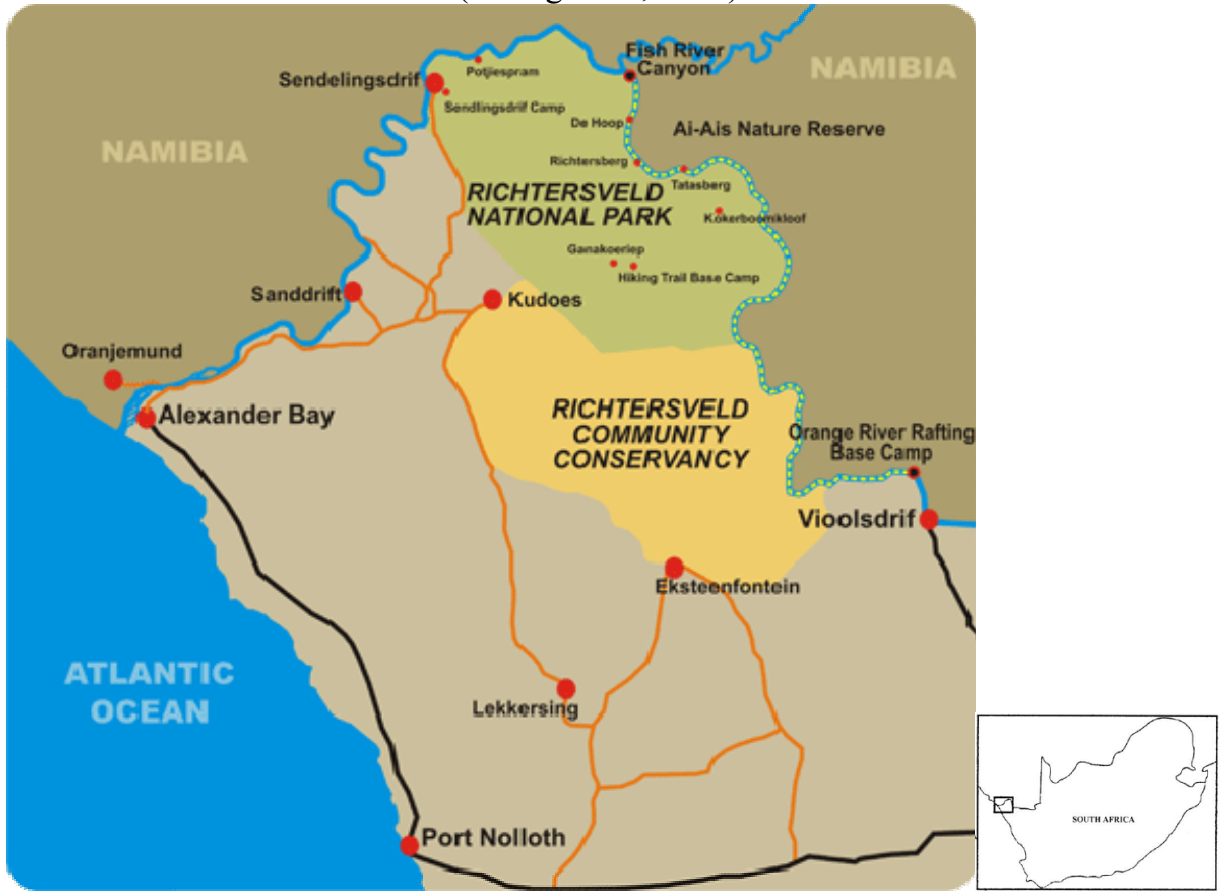

Figure 1: Map of Richtersveld National Park within Succulent Karoo in South Africa.

(Source: Mucina and Rutherfold, 2006)

The vegetation of the RNP is characterised by a variety of succulents, woody shrubs, diverse annuals and geophytes, with dwarf succulent shrubs of the family Aizoaceae being the most distinctive family in the Succulent Karoo. Trees mainly occur nearby the Orange River that flows along the northern and eastern boundary of the park. Five vegetation types are found in RNP. These are Central Richtersveld Mountain (CRM) and Northern Richtersveld Scorpionstailveld (NRS) in the Succulent Karoo biome and Noms Mountain Desert (NMD), Richtersberg Mountain Desert (RMD) and Richtersveld Sheet Wash Desert (RSWD) were found in the desert biome (Mucina \& Rutherfold, 2006). There was a rain gauge in each of the 5 study sites in RNP. Rainfall data is usually recorded in RNP and forwarded to South Africa Weather Service head office in Pretoria, South Africa. Vegetation types in Succulent Karoo biome experience winter-rainfall climate. Monthly annual precipitation varies from $60-200 \mathrm{~mm}$, but most of the area record less than $90 \mathrm{~mm}$ per annum. At higher altitudes, especially on southwestern slopes, there is frequent occurrence of fog or cloud resulting into a significant improvement in water supply for plants. On the other hand, vegetation types found in the Desert biome experience high aridity and relatively higher temperatures compared to the western mountains of Succulent Karoo which are more often exposed to cooling air from the Atlantic Ocean. The rockiness and very harsh spectrum of habitat conditions limits plant growth in most parts. Sparse dwarf shrubland were common in 
the vegetation types found in Desert Biome. Rainfall seasonality has transitional features between winter and summer rainfall, and is poorly predictable. In the Desert biome, high temperatures in summer are common with very few frost days per year. Fog does not play an important role unlike in the western sides of the Succulent Karoo biome.

Soils in the Richtersveld are shallow due to presence of hardpans at superficial depths in the valley (Mucina \& Rutherfold, 2006). Availability of soil water is the major driving force in plant growth and development especially in an area with extreme climatic variation such as RNP. In addition, Succulent Karoo soils are well suited to favour diverse plant species found in the area due to nutrients supply from the continuous weathering and mineralization process (Mucina \& Rutherfold, 2006). The RNP is a contractual park that is managed jointly by South African National Parks and the Richtersveld community. Semi-nomadic pastoralism has been practised in the Richtersveld for about 2000 years (Mucina \& Rutherfold, 2006). There is resource use partitioning in the RNP with different landforms being utilized at different times of the year. During the wet seasons (May-August) animals utilize forage in the mountains and plains while in the dry summer period (September - April) they move to the riparian zone of the Orange River due to availability of browse forage and water.

In the larger Richtersveld grazing land is still under the system of communal land ownership (Hendricks et al., 2004). Communal land ownership is based upon membership and a series of rights and duties with respect to the use of the land. Each pastoralist has the right to access the communal grazing areas which provides forage and water for their goats and sheep. Grazing arrangements was by consensus among the pastoralists. The pastoralists (Nama people) graze their livestock (mainly goats and sheep) in the park, and they move between stock posts at varying intervals in response to forage and water availability (Hendricks et al., 2004). Stock posts are designated semi-permanent residential points in RNP (Figure 2), where pastoralists settle with their animals, and after day long grazing, they return with their animals to these resting places overnight

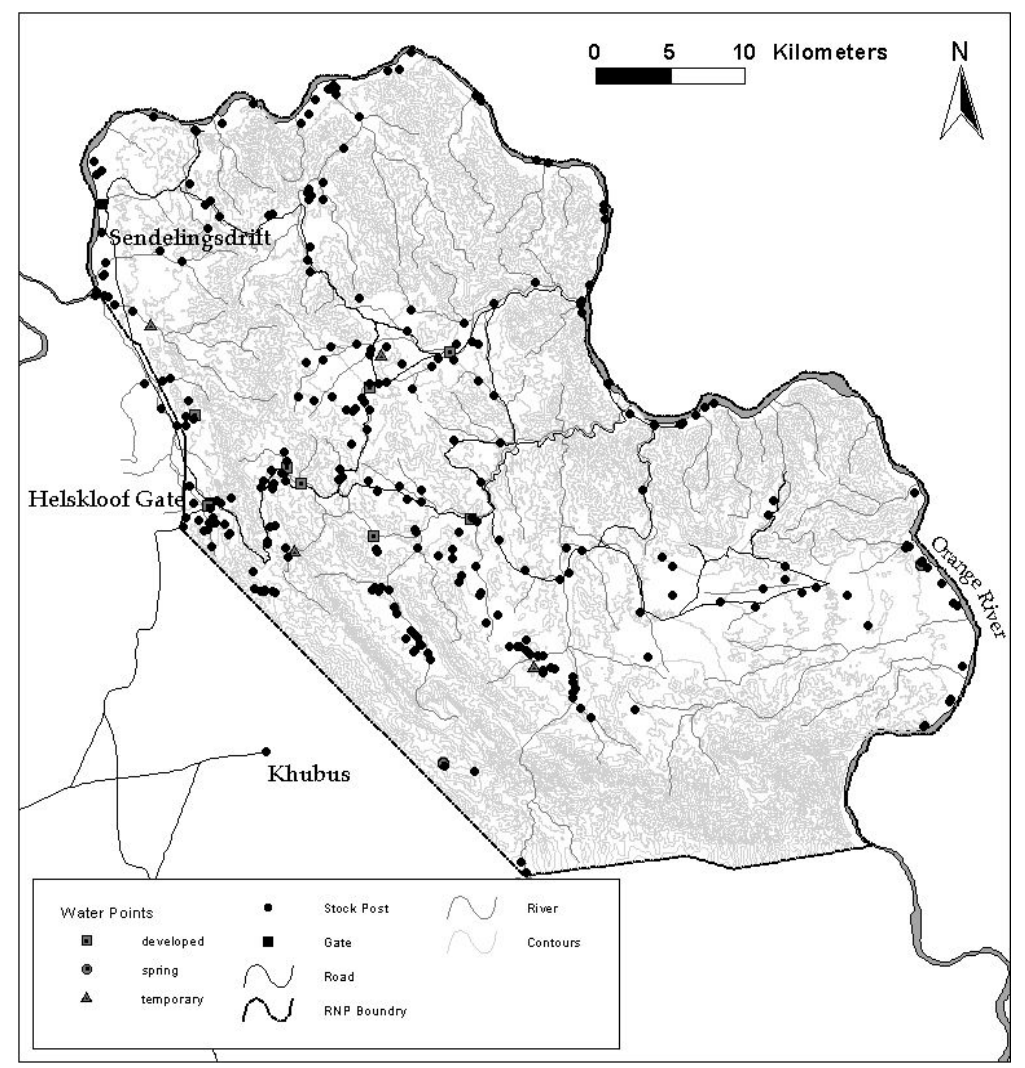

Figure 2: Distribution of stock posts (black dots) in Richtersveld National Park (Source: Hendricks et al., 2005)

\subsection{Vegetation Sampling}

Sampling was stratified in the 5 different vegetation types found in the RNP. Sampling points were selected in each vegetation type based on their proximity to an occupied stock post, proximity to a rain gauge in each vegetation type and occurrence of both foothill and flat plains. In each sampling site, 5 occupied stock posts and near the rain gauge were identified and two $1000 \mathrm{~m}$ transects were laid from the center of the stock posts, one on sandy flat plains and one on rocky steep foothills, at $(100 \mathrm{~m}, 500 \mathrm{~m}$ and $1000 \mathrm{~m}$ from stock posts. Mobile exclosures (of $1 \times 1 \mathrm{~m}$ ) were placed at 100, 500 and $1000 \mathrm{~m}$ from the stock posts to exclude grazing. At each 
harvesting date, all annual plants were clipped inside the exclosures and in adjacent $1 \mathrm{~m}^{2}$ plots outside the exclosures in July and September. Exclosures were relocated after every 2 months.

\subsection{Soil sampling and analyses}

Soil samples were collected at the sites of each exclosures at the same time as plant samples. Four soil samples were collected from each sampling plot at a depth of 0-15 cm (Jeddi \& Chaieb, 2010), mixed together and placed in a polythene bag. The soil analyses were conducted at BemLab laboratory (Stellenbosch, South Africa). The following analyses were carried out for each soil sample; soil $\mathrm{pH}$, sodium, potassium, calcium, magnesium, total nitrogen, phosphorus, organic carbon, electrical conductivity and percentage of sand, clay and silt.

\subsection{Rainfall data}

The monthly rainfall data for the 5 rain gauges in the 5 vegetation types were obtained from South Africa Weather Service in Pretoria, South Africa.

\subsection{Data Analysis}

To test for differences in biomass production, species richness and diversity with distance from the stock posts, between landscapes, years and vegetation types, ANOVA analysis was used. To analyze the differences in soil nutrient concentrations and forage consumption with distance from the stock posts $(100,500$ and $1000 \mathrm{~m})$ and between landscapes, two-factor ANOVA was used. The relationships between rainfall and biomass production, species richness and diversity were determined by use of linear regression. In order to determine the influence of environmental variables on plant species composition and distribution, ordination was done using Canonical Correspondence Analysis (CCA) on vegetation data. The environmental variables were first tested for multicollinearity whereby variables with close correlations were excluded from the CCA analysis. Environmental variables were square-root transformed due to variance of units of measurements. In CCA output, very rare species and outliers were excluded from the ordination analysis.

\section{RESULTS}

\subsection{Effect of grazing and landforms on annual plants}

Biomass production of annuals did not differ significantly with distances from the stock posts and within landscapes as shown in Table 1. However, biomass production differed significantly between the two years of study $\left.\left(\mathrm{F}_{1,58}\right)=36.9, \mathrm{P}<0.05, \mathrm{n}=60\right)$. Species richness differed significantly with distance from the stock posts $\left.\left(\mathrm{F}_{2,57}\right)=3.12, \mathrm{P}=0.05, \mathrm{n}=60\right)$ and also between the two years of study $(\mathrm{F}(1,58)=0.04, \mathrm{P}=0.05, \mathrm{n}=60)$. However species richness did not differ significantly between the two landscapes (plains and foothills) as shown in Figure 3a-c. Species diversity differed significantly with distance from the stock posts $\left(\mathrm{F}_{2,57}\right)=6.74, \mathrm{P}=0.05$, $\left.\mathrm{n}=60\right)$ and also within the two landscapes $\left.\left(\mathrm{F}_{1,58}\right)=4.7, \mathrm{P}<0.05, \mathrm{n}=60\right)$. On the other hand, species diversity of annual plants did not differ significantly between the two years of study as shown in Table 1 and in Figure 3a-c.

Table 1: Effect of distance from the stock posts, land form and rainfall on biomass production, species richness and diversity

\begin{tabular}{|l|lll|}
\hline $\begin{array}{l}\text { Plant } \\
\text { parameters }\end{array}$ & Distance & Landforms & Rainfall \\
\hline $\begin{array}{l}\text { Biomass } \\
\text { production }\end{array}$ & $\mathrm{F}_{(2,57)}=3.12$ & $\mathrm{~F}_{(1,58)}=0.52$ & $\mathrm{~F}_{(1,58)}=36.90$ \\
& $\mathrm{P}>0.05$ & $\mathrm{P}>0.05$ & $\mathbf{P}<\mathbf{0 . 0 5}$ \\
& $289 \pm 6$ & $302 \pm 8$ & $316 \pm 11$ \\
Species & & & \\
richness & $\mathrm{F}_{(2,57)}=3.12$ & $\mathrm{~F}_{(1,58)}=0.04$ & $\mathrm{~F}_{(1,58)}=41.65$ \\
& $\mathbf{P}<\mathbf{0 . 0 5}$ & $\mathrm{P}>0.05$ & $\mathbf{P}<\mathbf{0 . 0 5}$ \\
Species & $0.8 \pm 0.2$ & $0.7 \pm 0.1$ & $0.8 \pm 0.2$ \\
Diversity & & & \\
& & & $\mathrm{F}_{(1,58)}=0.11$ \\
& $\mathrm{~F}_{(2,57)}=6.74$ & $\mathrm{~F}_{(1,58)}=4.77$ & $\mathrm{P}>0.05$ \\
& $\mathbf{P}<\mathbf{0 . 0 5}$ & $\mathbf{P}<\mathbf{0 . 0 5}$ & $0.8 \pm 0.1$ \\
& $0.7 \pm 0.2$ & $0.7 \pm 0.2$ & \\
\hline
\end{tabular}

$(\mathrm{n}=60)$. The values marked $*$ show significant difference at $\mathrm{P} \leq 0.05$. 


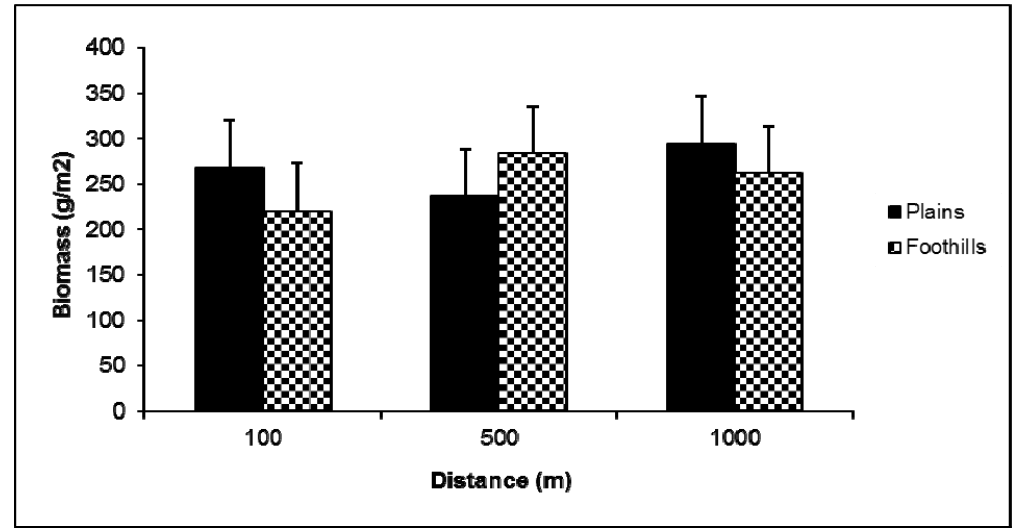

(a)

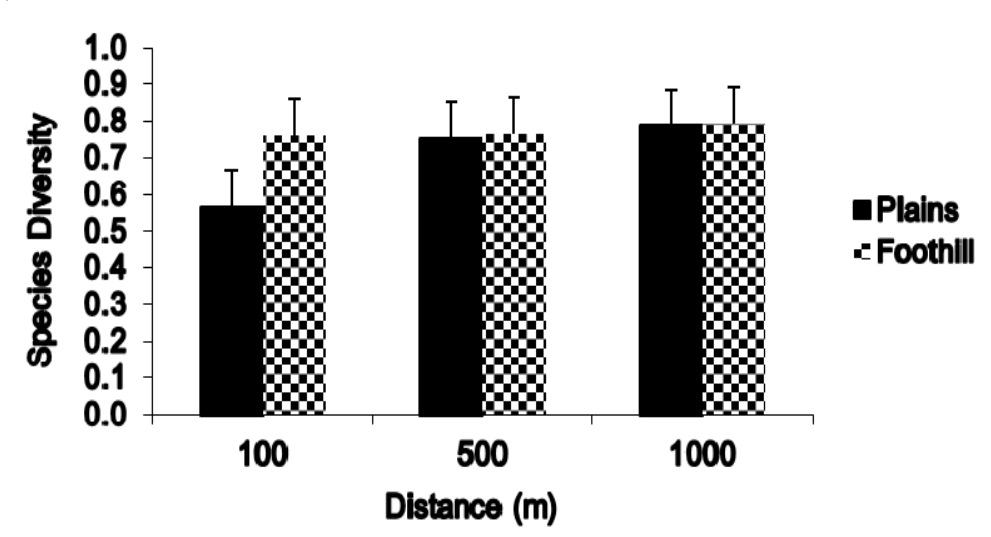

(b)

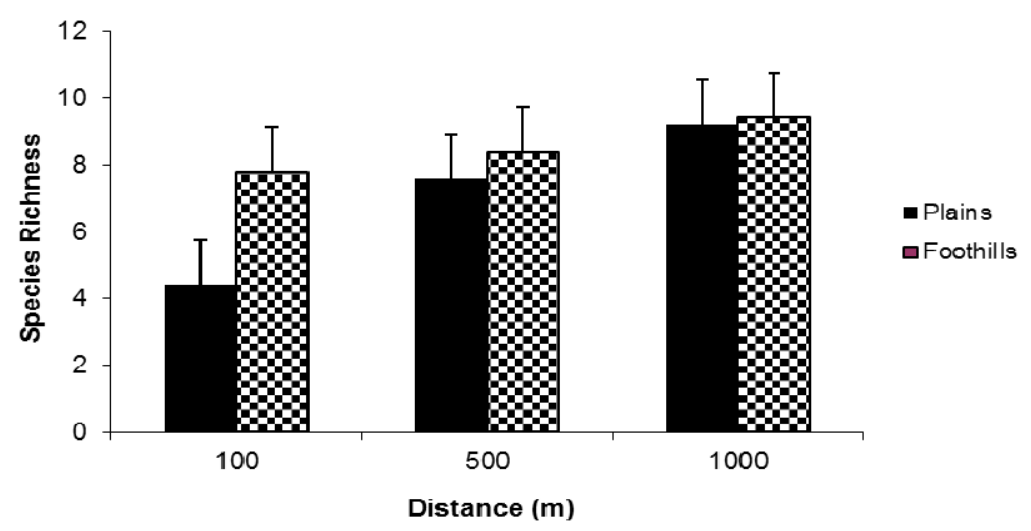

(c)

Figure 3a-c: Effect of grazing (distance from stock posts) on biomass production, species diversity and richness of annual plants

Concerning the effects of landforms and distances from stock posts on soil properties, calcium and carbon did not differ significantly with distance from the stock posts and also between the two landscapes (Table 2). However, magnesium, phosphorus, sodium, nitrogen and $\mathrm{pH}$ differed significantly with distances from the stock posts and between the two landscapes (plains and foothills) with P-value less than 0.05 as shown in Table 2. 
Table 2: Variation of concentration of soil variables along grazing gradient and land forms.

\begin{tabular}{|l|l|l|l|}
\hline Soil Nutrients & Distance & Land forms & Distance $\mathbf{x}$ Land forms \\
\hline Calcium & $\mathrm{P}>0.05 ; \mathrm{F}_{(2,23)}=5.34$ & $\mathrm{P}>0.05 ; \mathrm{F}_{(1,23)}=1.6$ & $\mathrm{P}>0.05 ; \mathrm{F}_{(2,23)}=0.24$ \\
\hline Magnesium & $\mathbf{P}<\mathbf{0 . 0 5} ; \mathrm{F}_{(2,23)}=4.58$ & $\mathrm{P}>0.05 ; \mathrm{F}_{(1,23)}=0.04$ & $\mathrm{P}>0.05 ; \mathrm{F}_{(2,23)}=0.43$ \\
\hline Phosphorus & $\mathbf{P}<\mathbf{0 . 0 5} ; \mathrm{F}_{(2,23)}=5.90$ & $\mathbf{P}<\mathbf{0 . 0 5} ; \mathrm{F}_{(1,23)}=6.84$ & $\mathrm{P}>0.05 ; \mathrm{F}_{(2,23)}=1.79$ \\
\hline Sodium & $\mathbf{P}<\mathbf{0 . 0 5} ; \mathrm{F}_{(2,23)}=2.78$ & $\mathrm{P}>0.05 ; \mathrm{F}_{(1,23)}=0.039$ & $\mathrm{P}>0.05 ; \mathrm{F}_{(2,23)}=0.03$ \\
\hline Nitrogen & $\mathbf{P}<\mathbf{0 . 0 5} ; \mathrm{F}_{(2,23)}=3.30$ & $\mathbf{P}<\mathbf{0 . 0 5} ; \mathrm{F}_{(1,23)}=6.93$ & $\mathrm{P}>0.05 ; \mathrm{F}_{(2,23)}=0.56$ \\
\hline Soil pH & $\mathbf{P}<\mathbf{0 . 0 5} ; \mathrm{F}_{(2,23)}=4.58$ & $\mathbf{P}<\mathbf{0 . 0 5} ; \mathrm{F}_{(1,23)}=9.51$ & $\mathrm{P}>0.05 ; \mathrm{F}_{(2,23)}=1.92$ \\
\hline Carbon & $\mathrm{P}>0.05 ; \mathrm{F}_{(2,23)}=1.8$ & $\mathrm{P}>0.05 ; \mathrm{F}_{(1,23)}=2.28$ & $\mathrm{P}>0.05 ; \mathrm{F}_{(2,23)}=.094$ \\
\hline EC & $\mathrm{P}>0.05 ; \mathrm{F}_{(2,23)}=1.96$ & $\mathrm{P}>0.05 ; \mathrm{F}_{(1,23)}=3.01$ & $\mathrm{P}>0.05 ; \mathrm{F}_{(2,23)}=0.78$ \\
\hline
\end{tabular}

The marked $*$ show significant difference at $\mathrm{P}<0.05$. (Units of measurements of soil parameters, $\mathrm{pH}-\mathrm{KCl}$, Phosphorus (Bay II - mg/kg, Exchangeable cations - Na, Mg, Ca, K- Cmol $(+) / k g$; Carbon - \%; EC - Mų )

3.2 Effect of rainfall on biomass production, species richness and diversity in different vegetation types Biomass production was significantly higher in Succulent Karoo vegetation types (NRS and CRM) than in desert biome vegetation types (NMD, RMD and RSWD). Species richness and diversity were significantly higher in Succulent Karoo vegetation types (NRS and CRM) than in desert biome vegetation types (RMD and RSWD) (Figure 4). In Succulent Karoo biome, biomass production did not differ significantly between the 2 vegetation types. However in Desert Karoo, biomass production in NMD was significantly higher than in RMD and RSWD vegetation types. Species richness was higher in Succulent Karoo biome than in desert biome. In desert biome, species richness and diversity were significantly higher in NMD vegetation type than in the other 2 vegetation types (RMD and RSWD), while in Succulent Karoo species richness and diversity did not differ significantly between the 2 vegetation types (NRS and CRM) as shown in Figure 4a-c.

In 2006 the study area received the higher amount of rainfall in all the 5 vegetation types than in 2007. Also higher biomass production was recorded in 2006 than in 2007, which may be attributed to the difference in amount of rainfall. Species richness was higher in 2006 than in 2007 (Figure 4a) while species diversity did not show significant differences between the years (Figure 4b). Biomass production, species richness and diversity were also significantly $(\mathrm{P}<0.05)$ greater in vegetation types CRM and NRS found in the Succulent Karoo Biome than in vegetation types RMD, RSWD and NMD in desert biome (Figure 4a-c). This may be attributed to difference in amount of rainfall between the two years 

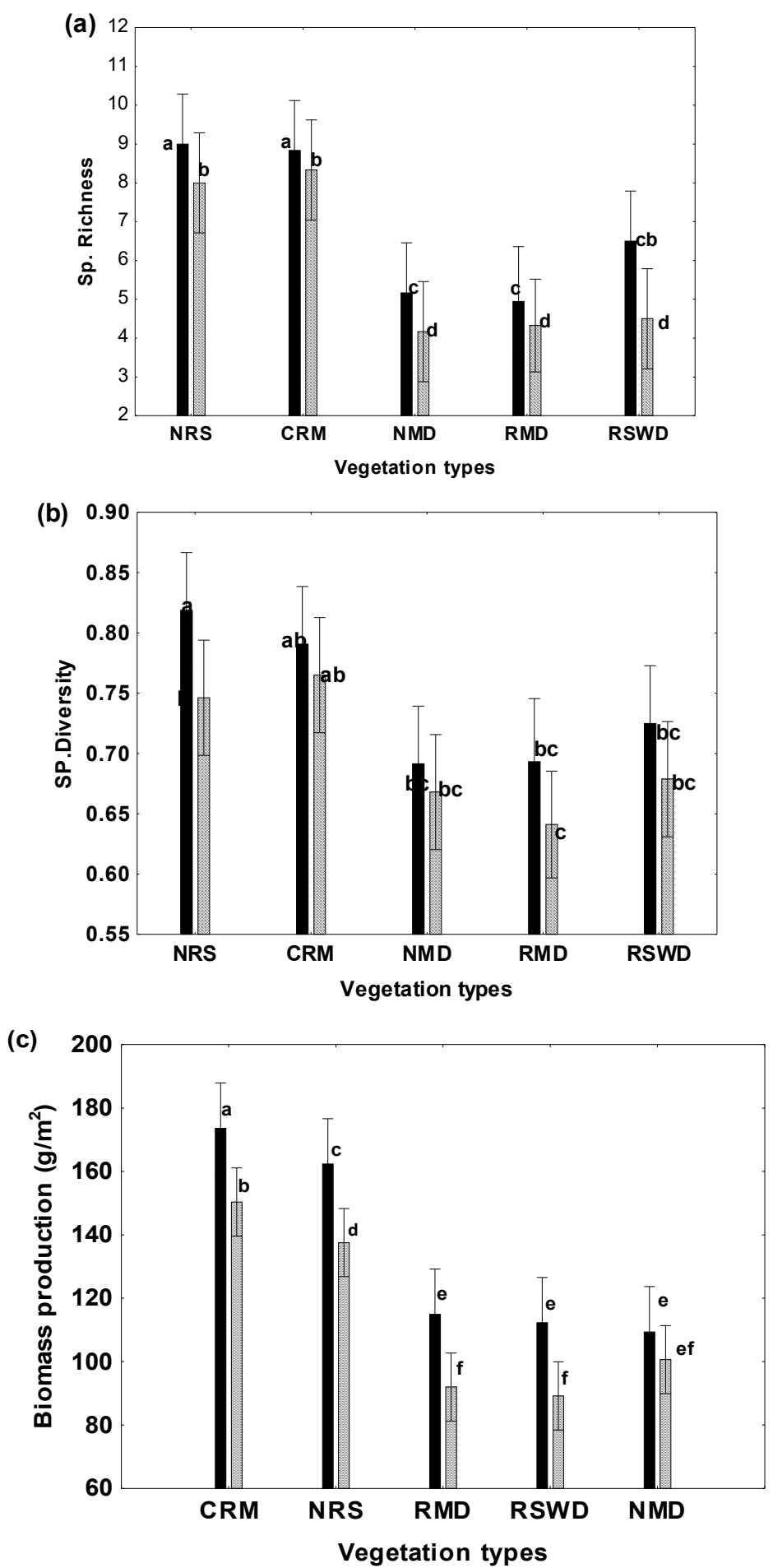

Figure 4a-c: Biomass, species richness and diversity in 5 vegetation types. 2006 ? 2007 Vertical bars denote 0.95 confidence intervals. Different letters denote significant difference while similar letters show no significant difference.

and between the vegetation types. Biomass production, species richness and diversity were positively correlated with rainfall as shown in Figure 5a-c. Biomass had a strong correlation with rainfall with $\mathrm{R}^{2}=0.7$, species richness with $\mathrm{R}^{2}=0.66$ while species diversity had correlation of $\mathrm{R}^{2}=0.64$ as shown in Figure 5a-c. 
(a)

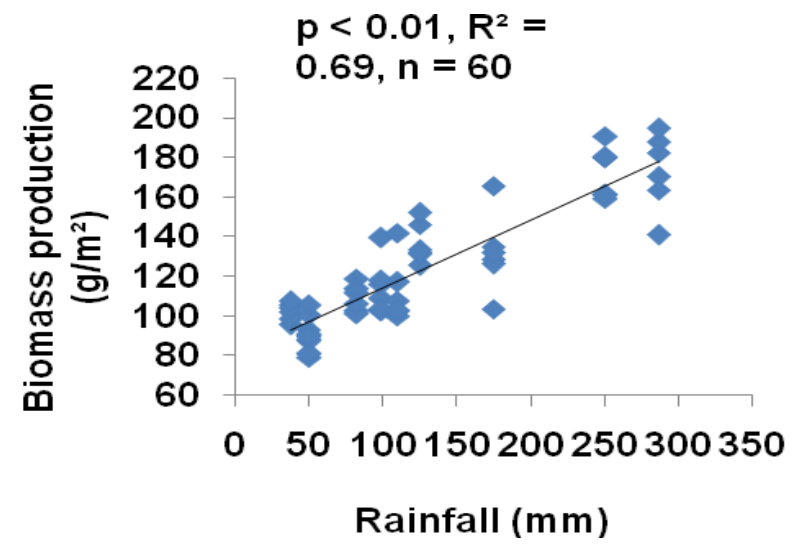

(b)

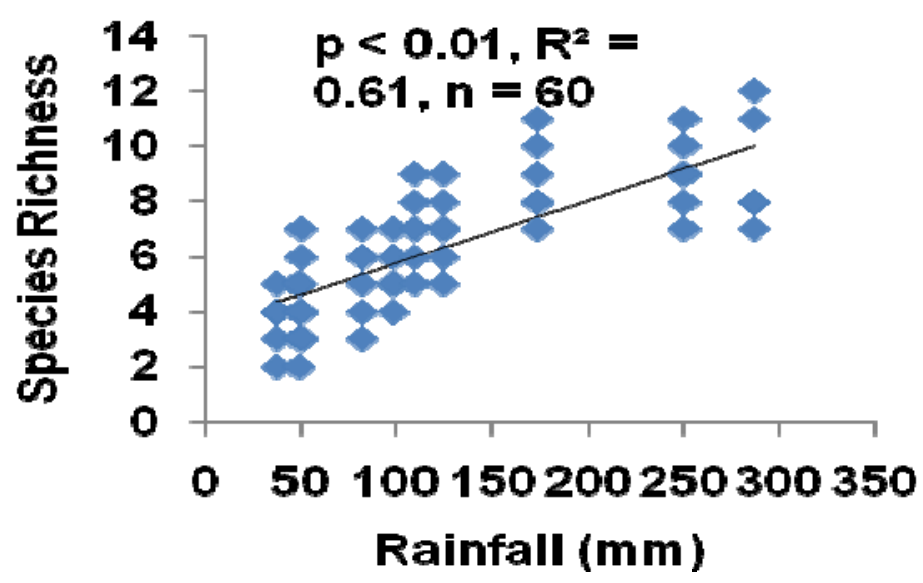

(c)

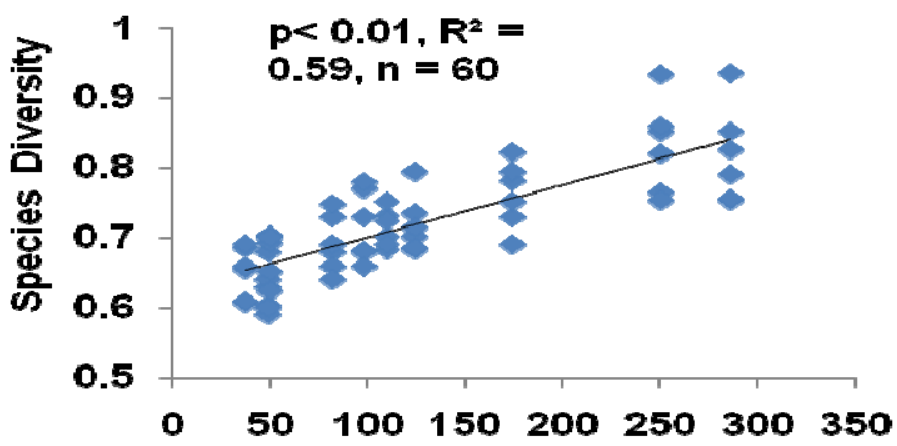

\section{Rainfall (m m)}

Figure 5a-c: Relationship between biomass, species richness and diversity with rainfall

\subsection{Effect of rainfall, grazing and soil variables on species composition}

Ordination was used in this study to order the arrangement of plant species in relation to each other in terms of the similarities of species composition and their associated environmental control variables. From the ordination diagrams (Figures 6 and 7) arrows pointing in the same direction indicate a high correlation while arrows crossing at right angles indicate near zero correlation and arrows pointing in roughly opposite direction indicate a high negative correlation. In the two vegetation biomes, it was found that rainfall had the greater influence on plant species composition than grazing (distance from the stock posts) and soil properties. In desert biome, the 
soil properties that had the greatest influence on plant species, included magnesium, phosphorous, EC and calcium (Figure 6). In the Succulent Karoo biome, soil pH, calcium, nitrogen and phosphorous had the greatest influence on distribution of plant species (Figure 7). Result shows that the effect of grazing that was represented by distances from stock post had less effect on composition of annual plants than rainfall.

In the desert biome, distribution of plant species Heliophila trifurca (Brassicaceae), Hypertelis salsoloides (Aizoaceae), Nemesia strumosa (Scrophulariaceae), Oncosiphon grandiflorum (Asteraceae) and Dimorphotheca sinuate (Asteraceae) were mainly influenced by calcium and nitrogen concentration in the soil while Dimorphotheca tragus (Asteraceae), Ornithoglossum viride (Colchicaceae), Cotula barbata (Asteraceae), Tribulus cristatus (Zygophyllaceae), Acanthopsis disperma (Acanthaceae) and Wahlenbergia sp. (Campanulaceae) were highly influenced by rainfall. On the other hand Mesembryanthemum nodiflorum (Aizoaceae), Amellus nanus (Asteraceae), Stoeberia beetzii var beetzi (Aizoaceae), Schmitdtia kalahariensis (Poaceae) and Oncosiphon suffruticosum (Asteraceae) were influenced by grazing (distances from stock posts) as shown in Figure 7.

In succulent Karoo biome, the distribution of plant species Gorteria personata (Asteraceae), S. beetzii var beetzii (Aizoaceae), and Nemesia anisocarpa (Scrophulariaceae) were highly influenced by $\mathrm{Mg}$ and Ca while Hirpicium echinus (Asteraceae), Pentizia incana (Asteraceae), Stoeberia beetzi (Aizoaceae) were influenced by grazing (distance from the stock posts). Plant species Amellus nanus (Asteraceae), Trianthema sp.(Aizoaceae), Oncosiphon grandiflorum (Asteraceae), Dimorphotheca sinuate (Asteraceae), Mesembryanthemum guerichianum (Aizoaceae) and Cotula barbata (Asteraceae) were closely associated with presence of phosphorus and nitrogen in soil while Vigna vexillata var. ovate (Fabaceae), Oncosiphon suffruticosum (Asteraceae), Schmitdtia kalahariensis (Poaceae), Heliophila trifurca (Brassicaceae) and Limeum africanum L. subsp. Africanum (Molluginaceae) were highly influenced by rainfall (Figure 7)

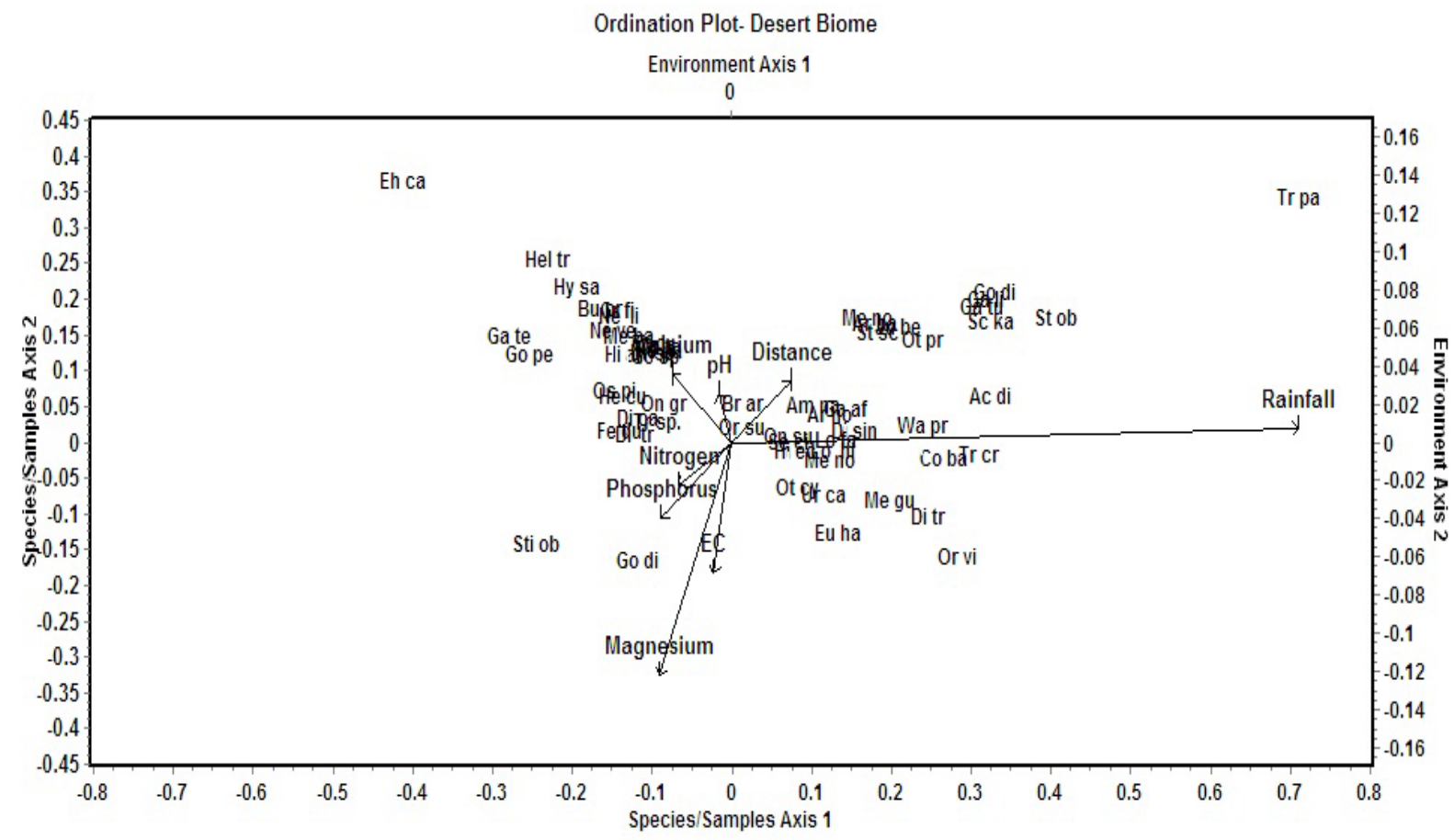

Figure 6: Biplot Ordination scatter diagram showing influence of environmental variables on distribution of plant species in Desert Biome in RNP. (Arrows represents environmental variable and abbreviated letters represents plant species 
Ordination Plot- Succulent Karoo Biome Environment Axis 1

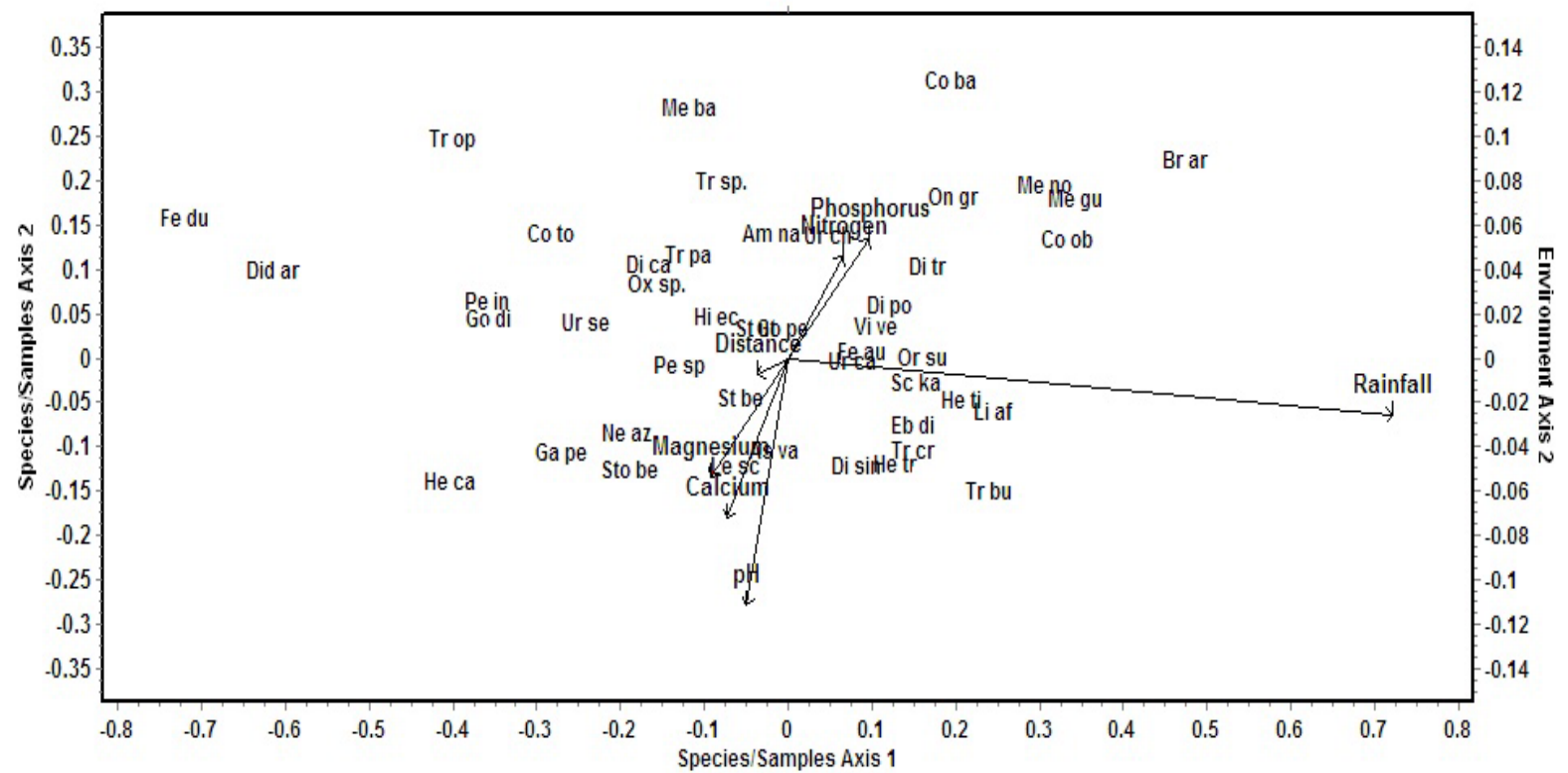

Figure 7: Biplot Ordination scatter diagram showing influence of environmental variables on distribution of plant species in Succulent Karoo Biome in RNP. (Arrows represents environmental variable and abbreviated letters represents plant species)

\begin{abstract}
4 Discussion
In the RNP just like in other arid and semi-arid rangelands rainfall was found to have a strong influence on spatial and temporal components of the annual plants. This can be attributed to the fact that during the rainy season a remarkable germination of annual plants occurs in drylands. The study shows that rainfall influenced biomass production of annual plants in all vegetation types in RNP. Vegetation types in the Succulent Karoo biome in the western side of RNP usually receive high winter rainfall than the Desert biome on the western side of the park. Desert biome part of the park received scattered summer rainfall and very little winter rainfall leading to an overall more erratic rainfall pattern, sometimes less than $80 \mathrm{~mm}$ per year (Hendricks et al., 2005b). Therefore the higher biomass production, species richness and diversity found in succulent Karoo biome was associated with high winter rainfall. Annual plants therefore play an important role as substitute source of forage for herbivores in arid and semi-arid rangelands especially immediately after a dry period as they germinate faster when the rainy seasons start.

Biomass production of annual plants did not differ significantly with distance from stock posts. This can be attributed to high level of grazing and trampling near the stock posts especially on the plains that would have led to low biomass of annual plants. On the other hand, species richness and diversity decreased with distance away from stock posts. These findings were consistent with Tarhouni et al., (2010), who reported higher species richness and diversity of annual plants near the vicinity of watering points. Less competition from perennials near the stock posts in addition to high concentration of soil nutrients from dung deposition would lead to high species richness and diversity closer to the stock posts. The results corroborate those of Sassi et al., (2009) who noted that areas with a high animal density are characterized by reduction of perennial species and abundance of annuals during rainy seasons. This is because strong and chronic disturbances of vegetation decrease the floristic richness and bring about a replacement of perennial species by annual herbaceous plants. These shifts in floristic composition also depend mainly on the disturbance impacted on soil properties (Tarhouni, et al., (2010). Annual plants species diversity was found to be higher on the plains than on foothills at a distance of $100 \mathrm{~m}$ but no differences in species richness and biomass production between the two landforms. High species richness and diversity is a characteristic feature of the succulent Karoo biome as reported by Anderson and Hoffman (2007) who also found higher perennial species diversity on the rocky foothills than on the sandy plains in a communally grazed land in Succulent Karoo. Therefore, in higher rainfall years, the bare spaces created by loss of larger plants due to grazing effects especially on flat plains are usually colonized by geophytes and annuals species and this leads to dominance of annual plants during the rainy seasons. Heavy grazing and daily trampling effect by animals near stock posts may have contributed to lack of significant difference in biomass production with distance from the stock posts.
\end{abstract}


Soil variables were found to have influence on biomass production, species richness and diversity. The observed increase in soil $\mathrm{pH}$, phosphorus, magnesium, sodium, and potassium near the stock posts in this study can be attributed to the high concentration of herbivores fecal pellet and urine around the stock posts. Effects of large quantities of animal dung and urine within the vicinity of stock posts in NRP led to the observed increase of $\mathrm{P}, \mathrm{Na}, \mathrm{Mg}$ and $\mathrm{K}$ contents. Similar findings had been reported by Smet and Ward $(2005 ; 2006)$ in arid rangelands whereby concentration of soil macro-elements were found to be higher near watering points than at distance away. The study showed that there was low level of nitrogen content in RNP. This may be attributed to the fact that nitrogen in the soil is usually utilized faster by plants for their growth, considering that the study was conducted during wet seasons when there was mass growth of annual plants. Stock et al., (1999) reported high concentration of nitrogen, phosphorus and organic carbon under the long-lived perennial shrubs than in the short-lived annual species. The observed increase in species richness and diversity of annual plants near the stock posts may be attributed to the high content of soil nutrients caused by piosphere effects. Biomass production of annual plants did not have significant change with distance from the stock posts. Therefore loss of palatable shrubs as a result of over-grazing in Succulent Karoo which was accompanied by dominance of shortlived annual plant species would consequently interfere with spatial distribution of soil nutrients and forage in these arid and semi-arid rangelands.

Patterns in plant species composition and distribution were mainly explained by rainfall and soil variables. This is due to differences in habitat conditions, ecological needs and tolerance range. From the ordination analysis, species composition and distribution were different in succulent and desert biomes. This shows that the two biomes exhibit different environmental and edaphic variables that supported different plant species composition. The soil variables that were found to influence plant species composition were magnesium, phosphorus, EC, $\mathrm{pH}$ and calcium. The CCA output showed that rainfall had greater influence on species composition in RNP than grazing (distances from stock posts) in both biomes. Grazing had very minimal influence on species composition both in Succulent Karoo and in Desert Biome compared to rainfall and soil variables. Also rainfall had overriding effects on species productivity, richness, diversity and composition than grazing. This shows how rainfall variability in Succulent Karoo affects annual plants species, forage availability and eventually the herbivore dynamics.

In the event that the predicted climate change effects (increased temperatures and unpredictable winter rainfall) occur in Succulent Karoo (Young et al., 2016), then loss of succulent plants in winter rainfall area such as RNP will have negative impact on primary productivity, species diversity, livestock farming and eventually on the livelihoods of communities that rely on pastoralism. The entire biodiversity of the Succulent Karoo biome would be affected. The question that needs to be addressed is whether these arid and semi-arid ecosystems such as RNP are ecologically resilient enough to withstand the effects of climate change scenario, in addition to the effects of unhealthy land use practices such as continuous communal grazing by pastoralists who rely on these arid ecosystems. The other question from conservation perspective was weather the continued loss of perennial plants due to overgrazing will be compensated by growth of short-lived annual plants that are rainfall dependent. The observed effects of climate change in combination with unsustainable land use practices such as grazing in RNP will be a great threat to biodiversity conservation in Succulent Karoo.

The herbivores did not exploit all the forage resources that were available in the flat plains, foothills and mountains during the wet seasons. This was in support of existence of a non-equilibrium dynamic in RNP ecosystem. On the other hand, during the dry season along the riparian zone, forage resource from trees reduced with time, and due to height effect, goats and sheep could reach forage up to a height of $1.5 \mathrm{~m}$. Therefore there was coupling of forage resources with herbivores with time as dry period continued. This was in support of an occurrence of an equilibrium dynamic in the riparian zone. The dynamics differed during the wet and dry seasons in RNP.

\section{Conclusion and recommendations}

Rainfall had greater impact on annual plants biomass production, species richness, diversity and distribution of plants species in RNP than grazing. Rainfall variability which is common in Succulent Karoo affects the productivity, diversity and composition of annual plants leading to variability in forage availability and distribution in different landscapes. Since annual plants are unreliable source of forage due to their high dependence on rainfall, decrease of perennials cover and biomass production near the stock posts that is not accompanied by increase in biomass production of annual plants will have unfavorable effects on the ecosystem as well as to the herbivores especially during the dry periods.

Piosphere effect around the stock posts was found to alter the distribution and composition of plants species as well as soil nutrients thus the need to abolish establishment of additional stock posts in the park. Deposition of animal pellets and urine around the stock post has affected the distribution of soil nutrients most of which decreased with increase in distance from the stock posts. Establishment of more stock posts in the area will only escalate this problem by spreading the piosphere effects to the other parts of the study area. The piosphere effects 
observed has greatly affected the equilibrium of forage supply to the herbivores. The most pronounced piosphere effect is the reduction of perennial vegetation cover and biomass production while on the other hand there is no compensation for this loss with annual plants because they are highly rainfall-dependent. This shows that during the dry periods there is likelihood of massive animal loss due to lack of forage. Study of plant species richness and diversity, soil nutrients distribution and the grazing gradient from the stock posts provides an opportunity to understand ecological processes in arid ecosystems. This is very important in formulation of management policies of arid and semi-arid rangelands. There is need to carry out an integrated ecological modelling in order to understand how the various biotic (rainfall, temperature) and abiotic factors (grazing intensity, soil variables, landforms) influence forage production and animals dynamics in RNP.

\section{Conflict of interest}

The authors declare that there is no conflict of interest in the publication of this paper

\section{Acknowledgements}

This work was financially supported by the South Africa National Research Foundation through Rhodes University, South Africa, and the Third World Organisation for Women in Science. We are grateful to the management and staff of the Richtersveld National Park for allowing us to access the park for data collection. Our gratitude goes to the pastoralists (Piet and Sanna Domrogh, Koos Diergaardt, Paul Cloete, Koos Jossob, and Joseph Domrogh) and field assistants for their support in data collection. We also acknowledge the South Africa Weather Service for providing the rainfall data.

\section{References}

Anderson, P. M. L., Hoffman, T. M. \& O'Farrell P. J. (2010). Above ground perennial plant biomass across an altitudinal and land-use gradient in Namaqualand, South Africa, South African Journal of Botany, 76, 471481

Anderson, P. M. L. \& Hoffman M. T. (2007). The impact of sustained heavy grazing on plant diversity and composition in lowland and upland habitats across the Kamiesberg mountain range in the Succulent Karoo, South Africa, Journal of Arid Environment, 70 (4), 686-700

Brooks, M. L., Matchett, J. R. \& Berry KH (2006). Effects of livestock watering sites on alien and native plants in the Mojave Desert, USA, Journal of Arid Environment, 67,125-147

Baker, L. E. \& Hoffmann, T. M. (2006). Managing variability, Herding strategies in communal rangelands of semi-arid Namaqualand, South Africa. Human Ecology, 34, 765-784

Deng, L., Sweeney, S. \& Shangguan, Z. P. (2013). Grassland responses to grazing disturbance, plant diversity changes with grazing intensity in a desert steppe. Grass and Forage Science, 69 (3), 524-533.

Fynn, R. S. W., \& O’Connor, T. G. (2000). Effect of stocking rate and rainfall on rangeland dynamics and cattle performance in a semi-arid savanna, South Africa, Journal of Applied Ecology, 37, 491-507

Gilson, L., \& Hoffman, M. T. (2007). Rangeland ecology in a changing world. Science, 315, 53-54.

Hendricks, H. H., Novellie, P. A., Bond, W. J., \& Midgley, J. J (2005a). Plant species richness and composition along livestock grazing intensity gradients in a Namaqualand South Africa protected area. Plant Ecology, $176,19-33$

Hendricks, H. H., Clark, B., Bond, W. J., Midgley, J. J., \& Novellie, P. A. (2005b). Movement response patterns of livestock to rainfall variability in Richtersveld National Park. African Journal of Range and Forage Science, 22 (2), 117-125

Jawuoro, S. O., Koech, O. K., Karuku, G. N, \& Mbau, J. S. (2017) Effect of piospheres on physio-chemical soil properties in the Southern Rangelands of Kenya, Ecological Processes, 6 (14), 1-7.

Jeddi, K. \& Chaieb, M. (2010). Changes in soil properties and vegetation following livestock grazing exclusion $\mathrm{n}$ in degraded arid environments of South Tunisia. Flora, 205,184-189

MacKellar, N. C., Hewiston, B. C., \& Tadross, M. A. (2007) Namaqualand's climate, Recent historical changes and future scenarios. Journal of Arid Environment, 70 (4), 604-614

Mucina L, Rutherfold MC (2006).The vegetation of South Africa, Lesotho and Swaziland, Pretoria, South Africa. 220- 299

Mucina, L., Jurgens, N., Le Roux, A., Rutherfold, M. C, Schmiedel, U., Esler, K. J., Powrie, L. W, Desmet, P. G. \& Milton, S. J. (2006). Succulent Karoo Biome. In, Mucina L, Rutherfold MC (Editors). The vegetation of South Africa, Lesotho and Swaziland, Pretoria, South Africa, PP 220- 299

Nsinamwa, M., Moleele, N. M., \& Sebego, R. J. (2005) Vegetation patterns and nutrients in relation to grazing pressure and soils in the sandveld and hardveld communal grazing areas of Botswana. African Journal of Range and Forage Science, 22 (1), $17-28$

Petersen, A., Young, E. M., Hoffman, M. T. \& Musil, C. F. (2004). The impact of livestock grazing on landforms biophysical attributes in privately and communally managed rangelands in Namaqualand, South 
Africa Journal of Botany, 70 (5), 777-783

Rutherfold, M. C., \& Powrie, L. W. (2010). Severely degraded rangeland, Implications for plant diversity from a case study in Succulent Karoo, South Africa. Journal of Arid Environment, 74, 692-70.

Sassi, P. L., Taraborelli, P. A., Borghi, C. E. \& Ojeda, R. A. (2009). Cattle grazing effects on annual plants assemblages in the Central Monte Desert, Argentina. Journal of Arid Environments, 73, 537-54.

Shahriary, E., Palmer, M. W., Tongway, D. J., Azarnivand, H., Jafari, M. \& Saravi, M. (2012). Plant species composition and soil characteristics around Iranian piospheres. Journal of Arid Environments, 82,106-114.

Smet, M., \& Ward, D. (2005). A comparison of the effects of different rangeland management systems on plant species composition, diversity and vegetation structure in a semi-arid savanna. African Journal of Range and Forage Science, 22 (1), 59-71.

Smet M, \& Ward, D. (2006). Soil quality gradients around water points under different management systems in a semi-arid savannah, South Africa, Journal of Arid Environment, 64, 251-269.

Tarhouni, M. F., Salem, B., Belgacem, A. O., \& Neffati, M. (2010). Acceptability of plant species along grazing gradients around watering points in Tunisia arid zone. Flora - Morphology, Distribution, Functional Ecology of Plants, 205, (7) 454-466.

Tefera, S. (2013). Rangeland degradation in semi-arid Swaziland, effects of dip-tanks on herbaceous vegetation and soil properties. African Journal of Range and Forage Science, 8, 1-14.

Todd, S. W., and Hoffman, M. T. (2009). A fence-line in time demonstrates grazing-induced vegetation shifts and dynamics in the semi-arid Succulent Karoo. Ecological Applications, 19, 1897-1908

van Rooyen, M. W., \& Henstock, R., van Rooyen, N., \& van der Merwe, H. (2010). Plant diversity and flowering displays on old fields in the arid Namaqua National Park, South Africa, Koedoe 52 (1), 1-7.

van Rooyen, M. W., le Roux, A., Geldenhuys, C., van Rooyen, N., Broodryk, N. L. \& van der Merwe, H. (2015). Long-term vegetation dynamics (40 yrs) in the Succulent Karoo, South Africa, effects of rainfall and grazing. Applied Vegetation Science 18, 311-322

Young, J. A., Guo, D., Desmet, P. G. \& Midgley, G. F. (2016). Biodiversity and climate change, Risk to dwarf succulents in Southern Africa. Journal of Arid Environment, 129, 16-24. 